\title{
COMPARISON OF EFFECTIVENESS OF CARBAMAZEPINE VERSUS TOPIRAMATE FOR THE MANAGEMENT OF TRIGEMINAL NEURALGIA
}

\author{
Ramish Tariq, Omer Sefvan Janjua, Sana Mehmood, Muhammad Usman Khalid, Khurram Jah Zafar, Saad Hameed \\ Allied Hospital, Faisalabad Pakistan
}

\begin{abstract}
Objective: To compare the effectiveness of Carbamazepine versus Topiramate for the management of trigeminal neuralgia. Study Design: Comparative prospective study.

Place and Duration of Study: Oral and Maxillofacial Surgery department, Allied Hospital, Faisalabad Pakistan, from Nov 2017 to Nov 2018.

Methodology: A total of 60 patients (30 in each group) were included. Group A was treated with Carbamazepine 100mg TDS and group B with Topiramate $25 \mathrm{mg}$ TDS. Visual analogue scale was used to access pain and was calculated at $1^{\text {st }}$ visit (baseline), at $7^{\text {th }}$ day, at $14^{\text {th }}$ day and at $28^{\text {th }}$ day.

Results: Out of 60 patients, mean of age was $54.78 \pm 8.49$ years. Right and left side of the face was involved in $41(68.3 \%)$ and $19(31.7 \%)$ patients respectively. Maxillary branch was involved in $24(40 \%)$ and mandibular branch was involved in $36(60 \%)$ patients. The mean of visual analogue scale after 7 days in group A was $4.53 \pm 0.93$ and in group B was $7.1 \pm 1.07$, after 14 days mean of visual analogue scale in group A was $3.7 \pm 1.02$ and in group B was $4.03 \pm 1.27$. Mean of visual analogue scale after 28 days in group A was $3.27 \pm 1.013 .93 \pm 1.28$. The results were statistically significant with $p$-value of 0.03 .

Conclusion: Topiramate has comparable efficacy as that of Carbamazepine at dose of $75-100 \mathrm{mg}$ with lesser side effects. So Topiramate can be used as first line of treatment in trigeminal neuralgia.
\end{abstract}

Keywords: Carbamazepine, Topiramate, Trigeminal neuralgia.

This is an Open Access article distributed under the terms of the Creative Commons Attribution License ( https://creativecommons.org/licenses/by-nc/4.0/), which permits unrestricted use, distribution, and reproduction in any medium, provided the original work is properly cited.

\section{INTRODUCTION}

Trigeminal neuralgia (TN) also called as tic doulourex is defined as severe, sharp, sudden, and stabbing pain that is unilateral and occurs in one or more divisions of trigeminal nerve ${ }^{1,2}$. Pain is triggered by nonnoxious stimuli like yawning, washing of face, brushing teeth and eating or it may be spontaneous in nature with pain free intervals. TN is classified as classical, secondary and idiopathic ${ }^{3}$. Incidence of TN is $0.7-27$ per 100,000 approximately ${ }^{4}$. Peak age of onset ranges from 35-72 years with female to male ratio of 3:2.35. Mandibular division and right side of the face is more commonly affected ${ }^{3}$.

TN can be treated medically as well as surgically with medical management considered the primary treatment option. Carbamazepine (CBZ) is the first line of treatment for the management of $\mathrm{TN}^{2}$. CBZ acts by keeping the voltage gated sodium channel in inactivated state. Reduction in pain is achieved within 24 hours $^{6}$. CBZ is associated with side effects like drowsiness, dizziness, nausea, vomiting, hepatotoxicity, myelosuppression, aplastic anemia, hyponatremia, renal toxicity, constipation, urinary retention and cardiac dysfunction and decrease in efficacy after prolong use

Correspondence: Dr Ramish Tariq, House No. 118B, Canal Expressway, Faisalabad Pakistan

Received: 03 Jan 2021; revised received: 02 Mar 2021; accepted: 05 Mar 2021 due to auto-induction 7 . Other medical options include drugs like Oxcarbazepine, Lamotrigine, Topiramate, Gabapentin, Baclofen and Phenytoin ${ }^{8}$. Topiramate is found to be effective for the treatment of trigeminal neuralgia with lesser side effects. Topiramate is d-fructose derivative and acts by blocking sodium, calcium channels and GABA agonist ${ }^{9}$. Dizziness, ataxia, constipation, bad taste and paresthesia like side effects are reported at higher doses ${ }^{10}$.

The rationale of study was to compare the effectiveness of Topiramate with Carbamazepine for the treatment of TN, as CBZ is associated with more side effects and its efficacy decreases over time. So that an effective and safe alternate of CBZ will be introdu-ced and prescribed to patients for the management of TN.

\section{METHODOLOGY}

A comparative prospective study was conducted in Oral and Maxillofacial Surgery department, Allied Hospital, Faisalabad Pakistan, from December 2017 to December 2018. Sample size was calculated using WHO calculator for two proportions: $\mathrm{P} 1=75 \%, 1 \mathrm{P} 2=$ $25.7 \%, 5$ power of study $=90 \%$, level of significance $=5 \%$ Sample size 60 (30 in each group). Consecutive nonprobability was the sampling technique. This study was approved from Hospital ethics review committee (ltr no: 835/2017). Newly diagnosed cases with age between 35-70 years, irrespective of gender were 
included in the study. Patients allergic to Carbamazepine or Topiramate, with comorbidities, post-traumatic neuropathic pain were excluded from the study.

After taking informed consent from the patients, history, clinical examination was done. Detailed history about the nature of pain was taken and diagnosis of trigeminal neuralgia was made based on the typical characteristics of pain. OPG was done to rule out any dental cause of pain. Renal function test and liver function test were done. Patients allocated into group A and B using lottery method. Group A was treated with Carbamazepine 100mg TDS and group B was treated with Topiramate 25mg TDS. Visual analogue score (VAS) was used to assess the severity of pain. VAS was calculated at baseline ( $1^{\text {st }}$ visit), after 7 days of start of drugs ( $2^{\text {nd }}$ visit), after 14 days ( $3^{\text {rd }}$ visit), after 21 days ( $4^{\text {th }}$ visit). In case of relief of pain in both the groups same dose of the drugs were continued. Patients who did not show reduction in pain as well as no side effects, the dose of Carbamazepine was increased by $100 \mathrm{mg}$ up to maximum of $1200 \mathrm{mg} /$ day and the dose of Topiramate was increased by $25 \mathrm{mg}$ up to maximum of $400 \mathrm{mg}$ /day. Patients who reported with side effects at any visit as well as no reduction in pain, drug was discontinued, results were recorded and alternative treatment option was advised.

Data was analyzed using SPSS-22. For qualitative variables like gender, side of the face, branch involved, frequencies and percentages were calculated. For quantitative variables like VAS, age mean and standard deviation were calculated. Independent sample t-test was applied and $p$-value $<0.05$ was considered statistically significant.

\section{RESULTS}

Among 60 patients (30 in each group), the age range was 38-70 years with mean of $54.78 \pm 8.49$ years. Mean of age in group A was $54.93 \pm 8.01$ years group B was $54.63 \pm 9.09$ years. Out of 60 patients, 21 (35\%) were male and $39(65 \%)$ were female with male to female ratio of 1:1.8. In group A, $12(40 \%)$ were male and $18(60 \%)$ were female. In group B, $9(30 \%)$ patients were male and $21(70 \%)$ were female. Right side of the face was involved in $41(68.3 \%)$ and left side was involved in $19(31.7 \%)$ patients (table-I).

Among 60 patients none of the patient reported with involvement of V1 division of trigeminal nerve. V2 was affected in $24(40 \%)$ patients and V3 was affected in $36(60 \%)$ patients (table-II). The mean of VAS at 1st visit (baseline) was $7.53 \pm 0.50$ in group $\mathrm{A}$ and 7.57 \pm 0.50 in group B. VAS after 7 days in group A was $4.53 \pm 0.93$ and in group $B$ was $7.1 \pm 1.07$, after 14 days mean of VAS in group A was $3.7 \pm 1.02$ and in group B was $4.03 \pm 1.27$. Mean of VAS after 28 days in group A was $3.27 \pm 1.01$ and in group $B$ was $3.93 \pm 1.28$. $p$-value was 0.03 (table-III).

Table-I: Frequency of side of the face involved in trigeminal neuralgia.

\begin{tabular}{l|c|c|c}
\hline $\begin{array}{l}\text { Side of } \\
\text { the face }\end{array}$ & $\begin{array}{c}\text { Group A } \\
\mathbf{n}(\mathbf{0})\end{array}$ & $\begin{array}{c}\text { Group B } \\
\mathbf{n}(\mathbf{0})\end{array}$ & $\boldsymbol{p}$-value \\
\hline Right & $19(63 \%)$ & $22(73 \%)$ & \multirow{2}{*}{0.4} \\
\hline Left & $11(36 \%)$ & $8(26.6 \%)$ & \\
\hline
\end{tabular}

Table-II: Frequency of branch of trigeminal nerve involved in trigeminal neuralgia.

\begin{tabular}{l|c|c|c}
\hline $\begin{array}{l}\text { Branch of V } \\
\text { nerve involved }\end{array}$ & $\begin{array}{c}\text { Group A } \\
\mathbf{n}(\mathbf{\%})\end{array}$ & $\begin{array}{c}\text { Group B } \\
\mathbf{n}(\mathbf{\%})\end{array}$ & $\boldsymbol{p}$-value \\
\hline V2 & $14(46.6 \%)$ & $10(73.3 \%)$ & \multirow{2}{*}{0.2} \\
\hline V3 & $16(53.3 \%)$ & $20(26.6 \%)$ & \\
\hline
\end{tabular}

Table-III: Pain score in groups.

\begin{tabular}{l|c|c|c}
\hline & Group A & Group B & $p$-value \\
\hline $\begin{array}{l}\text { Mean of pain score } \\
\text { at 1 }{ }^{\text {st }} \text { visit }\end{array}$ & $\begin{array}{c}7.53 \pm \\
0.507\end{array}$ & $\begin{array}{c}7.57 \pm \\
0.504\end{array}$ & 0.7 \\
\hline $\begin{array}{l}\text { Mean of pain score } \\
\text { 2nd visit }_{\text {(after 7 days of start }}\end{array}$ & $\begin{array}{c}4.53 \pm \\
0.937\end{array}$ & $\begin{array}{c}7.13 \pm \\
1.07\end{array}$ & 0.00 \\
of medication) & & & \\
\hline $\begin{array}{l}\text { Mean of pain score } \\
\text { at 3rd visit } \\
\text { (after 14 days of start } \\
\text { of medication) }\end{array}$ & 1.02 & 1.27 & 0.2 \\
\hline $\begin{array}{l}\text { Mean of pain score } \\
\text { at 4 visit }\end{array}$ & $3.27 \pm$ & $3.93 \pm$ & 0.03 \\
$\begin{array}{l}\text { (after 28 days of start } \\
\text { of medication) }\end{array}$ & 1.01 & 1.28 & \\
\hline
\end{tabular}

In group $\mathrm{A}$, dizziness was reported in 12 patients, drowsiness was in 5 and ataxia was reported in 1 patient at first follow up visit. The dose of CBZ was decreased in patients who showed reduction in pain score along with side effects like dizziness and drowsiness. In group B, 29 patients at first follow up visit did not show any side effects and only 1 patient reported with dizziness. At $2^{\text {nd }}$ follow up visit, 12 patients in group A reported with dizziness and 5 with drowsiness and in group B, 1 patient reported with nausea and 6 with numbness of extremities. The numbness was the only side effect in topiramate that disappeared with use of the medication without any interention. At $3^{\text {rd }}$ follow up visit 10 patients in group A complained of dizziness and 2 with drowsiness and in group B only 1 patient complained of dizziness (table-IV). 
Table-IV: Frequency of complications at follow up visits.

\begin{tabular}{|c|c|c|c|c|c|c|c|}
\hline Follow up Visit & Group & $\begin{array}{c}\text { No } \\
\text { Complication }\end{array}$ & Dizziness & Drowsiness & Nausea & $\begin{array}{c}\text { Numbness } \\
\text { of hands }\end{array}$ & Ataxia \\
\hline \multirow{2}{*}{$\begin{array}{l}\text { 1st follow up (after } 7 \text { days } \\
\text { of start of medication) }\end{array}$} & Group A & $12(40 \%)$ & $12(40 \%)$ & $5(16 \%)$ & - & - & $1(3 \%)$ \\
\hline & Group B & $29(96 \%)$ & $1(3 \%)$ & - & - & - & - \\
\hline \multirow{2}{*}{$\begin{array}{l}\text { 2nd follow up (after } 14 \\
\text { days of start of medication) }\end{array}$} & Group A & $13(43 \%)$ & $12(40 \%)$ & $5(16.6 \%)$ & - & - & - \\
\hline & Group B & $21(70 \%)$ & $2(6.6 \%)$ & - & $1(3 \%)$ & $6(20 \%)$ & - \\
\hline \multirow{2}{*}{$\begin{array}{l}\text { 3rd follow up (after } 28 \\
\text { days of start of medication) }\end{array}$} & Group A & $18(60 \%)$ & $10(33 \%)$ & $2(6.6 \%)$ & - & - & - \\
\hline & Group B & $29(96.6 \%)$ & $1(3 \%)$ & - & - & - & - \\
\hline
\end{tabular}

\section{DISCUSSION}

Trigeminal neuralgia is the most common and the most painful facial pain condition ${ }^{11}$. Treatment of $\mathrm{TN}$ is challenging and is managed medically in most of the patients. Surgical management is advised to patients who cannot tolerate the side effects of the drugs or who become resistant to various pharmacological options $^{12}$.

Toledo et al13, Katheriya et $a l^{14}$, found that TN was more prevalent in fourth to eighth decades of life. Kalyanaraman et al15, and Katusic et al16, also reported that the peak age of onset of TN is between $5-8^{\text {th }}$ decade of life. These results were in comparison to our study. The age range was 38-70 years with mean of 54.78 and SD of 8.49. Mean of age in group A was 54.93 \pm 8.01 years group $B$ was $54.63 \pm 9.09$ years.

In this study, out of 60 patients, 21 (35\%) were male and $39(65 \%)$ were female with male to female ratio of 1:1.8. Previous studies had also shown that females are predominately affected by Shah et alli, and Loh et al 18 , in their studies found female to male ratio of 2:1. Warraich et al, in their study found that $61 \%$ were female and $39 \%$ were male ${ }^{19}$.

Right side of the face was involved in 41 (68.3\%) and left side was involved in $19(31.7 \%)$ patients in our study. Neto et al, in their study also found right side was more commonly affected than the left side due to narrower foramen rotundum on right side of skull base $^{20}$. Siqueira et al, also found similar results ${ }^{21}$. In study conducted by Katheriya et al, right side was involved in $57.1 \%$ of cases and left side in $38.8 \%$ of cases ${ }^{14}$.

Among 60 patients in our study, V2 was affected in $24(40 \%)$ patients and V3 was affected in $36(60 \%)$ patients. No patient reported with V1 involvement. These results are in contrast to study conducted by Tine et al, who found that maxillary division was more commonly affected ${ }^{22}$. However, Loh et al found that mandibular division of trigeminal nerve was more commonly affected ${ }^{18}$. Katheriya et al, concluded that mandibular nerve was affected in $56.9 \%$, and maxillary nerve in $42 \%$ of cases $^{14}$,
Among 60 patients in our 2 patients were lost to follow up in group A and 1 patient was lost to follow up in group B. To complete the sample size 3 patients were added. In our study, VAS after 7 days in group A was $4.53 \pm 0.93$ and in group B was $7.1 \pm 1.07$, after 14 days mean of VAS in group A was $3.7 \pm 1.02$ and in group B was $4.03 \pm 1.27$. Mean of VAS after 28 days in group A was $3.27 \pm 1.01$ and in group $B$ was $3.93 \pm 1.28$. This shows that CBZ is effective after 7 days with dose of $300 \mathrm{mg} /$ day than Topiramate with dose of $75 \mathrm{mg} /$ day. But at $3^{\text {rd }}$ and $4^{\text {th }}$ visit Topiramate was equally effective as CBZ. Wang et al, also found Topiramate to be equally effective as that of CBZ after 1 month of use $^{9}$. Solaro et al, also showed in their study that Topiramate can be used effectively for the treatment of trigeminal neuralgia as an alternative to $\mathrm{CBZ}^{23}$. Campbell et al, found effectiveness of CBZ was $70-80 \%$ for the management of TN. They also found that CBZ was initially efficacy of CBZ was $80 \%$ that declines to $50 \%$ due to auto-induction ${ }^{24}$. Puri et al, described that CBZ was effective after 1 month of follow up in most of the patients but patients reported with side effects like nausea, drowsiness and vomiting 8 .

Wang et al, described that $15.8 \%$ of patients in their study using Topiramate showed side effects like dizziness, nausea, ataxia and confusion and $21.1 \%$ of patients with CBZ had side effects like dizziness, nausea, vomiting, fatigue and nystagmus. In comparison, in our study $40 \%$ patients with CBZ showed side effects and only 3.3\% with Topiramate had side effects 9 .

\section{LIMITATINO OF STUDY}

The major limitation with this study was small sample size i.e. 60 patients. This study should be conducted on a larger group of population. Secondly the patients were followed after one month only. CBZ showed resistance due to auto-induction and many side effects like hyponatremia, liver dysfunction and apl-astic anemia after long term use. As the follow up time was only of one month, these results were not found. Hence studies with longer follow ups should be conducted. 


\section{CONCLUSION}

Carbamazepine is more effective after one week but as the doze of Topiramate is increased to $75-100 \mathrm{mg}$ it is equally effective as that of Carbamazepine. However, Carbamazepine has more side effects than Topiramate. So Topiramate can be used for the treatment of trigeminal neuralgia with lesser side effects.

\section{CONFLICT OF INTEREST}

This study has no conflict of interest to be declared by any author.

\section{REFERENCES}

1. Di Stefano G, Truini A. Pharmacological treatment of trigeminal neuralgia. Expert Rev Neurother 2017; 17(10): 1003-11.

2. Yadav $Y R$, Nishtha $Y$, Sonjjay P, Vijay P, Shailendra R, Yatin K. Trigeminal Neuralgia. Asian J Neur 2017; 12(4): 585-97.

3. Bendtsen L, Zakrzewska JM, Heinskou TB, Hodaie M, Leal PRL, Nurmikko T, et al. Advances in diagnosis, classification, pathophysiology, and management of trigeminal neuralgia. Lancet Neurol 2020; 19(9): 784-96.

4. Kucuk AO, Keskinruzgar A. Prevalence of trigeminal neuralgia patients in the community: a retrospective study. J Clin Anal Med 2019; 10(1): 16-19.

5. Shafiq H, Badar MA, Qayyum Z, Saeed M. Effectiveness of carbamazepine versus oxycarbazepine in the management of trigeminal neuralgia. J Khyber Coll Dent 2015; 6(1): 32-35.

6. Kaur B, Dhir P. Evaluation of the efficacy of carbamazepine and gabapentin in the management of trigeminal neuralgia: A clinical study. J Indian Acad Oral Med Radiol 2018; 30(3): 253-56.

7. Chbili C, Hassine A, Ben Amor S, Nouira M, Ben Ammou S, Saguem S. Implications of metabolic parameters of carbamazepine in the therapeutic monitoring of Tunisian patients with epilepsy. Rev Neurol 2016; 172(4-5): 313-17.

8. Puri N, Rathore A, Dharmdeep G, Vairagare S, Prasad BR, Priyadarshini R, et al. A clinical study on comparative evaluation of the effectiveness of carbamazepine and combination of carbamazepine with baclofen or capsaicin in the management of trigeminal neuralgia. Niger J Surg 2018; 24(2): 95-99.

9. Wang QP, Bai M. Topiramate versus carbamazepine for the treatment of classical trigeminal neuralgia: a meta-analysis. CNS Drugs 2011; 25(10): 847-57.
10. Khalil BWA. Update on antiepileptic drugs 2019. Cont 2019; 25(2): 508-36.

11. Deun LV, Witte M, Goessens T, Halewyck S, Ketelaer MC, Matic M. et al. Facial Pain: a comprehensive review and proposal for a pragmatic diagnostic approach. Eur Neurol 2020; 83(1): 5-16.

12. Bick SKB, Eskandar EN. Surgical treatment of trigeminal neuralgia. Neurosurg Clin N Am 2017; 28(3): 429-38.

13. Toledo IP, Reus JC, Fernandes M, Porporatti AL, Peres MA, Takaschima A, et al. Prevalence of trigeminal neuralgia: a systemic review. J Am Dent Assoc 2016; 147(7): 570-76.

14. Katheriya G, Chaurasia A, Khan N, Iqbal J. Prevalence of trigeminal neuralgia in Indian population visiting a higher dental care center in north India. Natl J Maxillofac Surg 2019; 10(2): 195-99.

15. Kalyanaraman S, Ramamurthi B. Trigeminal neuralgia-a review of 331 cases. Neurol Ind 1970; 18(1): 100-108.

16. Katusic S, Beard CM, Bergstralh E, Kurland LT. Incidence and clinical features of trigeminal neuralgia, Rochester, Minnesota, 1945-1984. Ann Neurol 1990; 27(1): 89-95.

17. Shah SA, Murad N, Sallar A. Trigeminal neuralgia: analysis of pain distribution. Pak Oral Dent J 2008; 28(1): 37-41.

18. Loh HS, Ling SY, Shanmuhasuntharam P, Zain R, Yeo JF. Trigeminal neuralgia. A retrospective survey of a sample of patients in Singapore and Malaysia. Aust Dent J 1998; 43(3): 188-91.

19. Warriach RA. Intractable trigeminal neuralgia; comparison of neurectomy with cryosurgery as a treatment option. Professional Med J 2001; 8(2): 257-63.

20. Neto HS, Camilli JA, Marques MJ. Trigeminal neuralgia is caused by maxillary and mandibular nerve entrapment: Greater incidence of right-sided facial symptoms is due to the foramen rotundum and foramen ovale being narrower on the right side of the cranium. Med Hypotheses 2005; 65(6): 1179-82.

21. Siqueira SR, Teixeira MJ, Siqueira JT. Clinical characteristics of patients with trigeminal neuralgia referred to neurosurgery. Eur J Dent 2009; 3(3): 207-12.

22. Tine SD, Tamba B, Gassama BB, Niang P, Dia L, Kébé NF, et al. Clinical and therapeutic aspects of trigeminal neuralgia. Apropos of 27 cases treated at the general hospital of grand-yoffin Dakar. Odontostomatol Trop 2009; 32(126): 5-12.

23. Solaro C, Uccelli MM, Brichetto G, Gaspperini C, Mancardi G. Topiramate relieves idiopathic and symptomatic trigeminal neuralgia. J Pain Symp Manage 2001; 21(5): 367-68.

24. Campbell FG, Graham JG, Zilkha KJ. Clinical trial of carbazepine (tegretol) in trigeminal neuralgia. J Neurol Neur Psy 1966; 29(3): 265-67. 